\title{
UNIVERSIDADE PÚBLICA E INCLUSÃO SOCIAL:AS COTAS PARA AUTODECLARADOS NEGROS NA UNIVERSIDADE FEDERAL DO RIO GRANDE DO SUL*
}

\section{PUBLIC UNIVERSITY AND SOCIAL INCLUSION: THE RACIAL QUOTAS FOR SELF-DECLARED BLACKS IN THE FEDERAL UNIVERSITY OF RIO GRANDE DO SUL}

\begin{abstract}
RESUMO
A implementação de cotas raciais nas universidades públicas brasileiras é um processo recente e ainda em avaliação. Com o objetivo de analisar como essa experiência está ocorrendo, especialmente em sua efetividade enquanto ação inclusiva, realizou-se uma pesquisa quali-quantitativa, de caráter exploratório e descritivo, na Universidade Federal do Rio Grande do Sul. Os instrumentos utilizados, analisados por meio de triangulação, foram entrevistas com servidores e alunos, participação em diversas atividades institucionais e documentos. Os resultados indicam que a inclusão dos cotistas efetiva-se gradativamente na inserção no mundo do trabalho e nas dimensões acadêmicas da pesquisa e da extensão. Entre os aspectos que merecem maior atenção estão a visibilidade dada aos cotistas e a efetiva integração destes na instituição de ensino em todos os seus segmentos.
\end{abstract}

PALAVRAS-CHAVE Ações afirmativas, inclusão social, políticas públicas, sistema de cotas, universidade.

\author{
Maria Cristina Lunardi Kern cristina@esef.ufrgs.br \\ Universidade Feevale \\ Graduada em Educação Física pelo Instituto Metodista de Porto Alegre (IPA) e mestre em Educação Física pela Universidade Feevale, Novo Ham- \\ burgo (RS)
}

Denise Macedo Ziliotto dmziliotto@feevale.br

Professora titular e pesquisadora no Mestrado em Inclusão Social e Acessibilidade da Universidade Feevale de Novo Hamburgo (RS); coordenadora do Curso de Especialização em Psicologia do Trabalho e das Organizações nessa mesma instituição

Graduação em Psicologia e em Jornalismo pela Pontifícia Universidade Católica do Rio Grande do Sul, mestrado em Administração pela Universidade Federal do Rio Grande do Sul e doutorado em Psicologia Social pela Universidade de São Paulo

Artigo submetido em 26.09.2011 e aprovado em 16.12.2011.

\begin{abstract}
The implementation of racial quotas in Brazilian public universities is a recent process still under evaluation. In order to analyze how this experience has been realized, particularly in its success as an inclusive action, a quali-quantitative research of an exploratory and descriptive character was carried out, at Universidade Federal do Rio Grande do Sul. The research instruments used were interviews with the staff and the students, attendance to many institutional activities and documentary sources, all analyzed through triangulation. The results indicate that the inclusion of quota students is gradually actualized in their placement in the job market and in the academic realms of research and public outreach. Among the aspects that deserve further attention are the visibility given to these students and their effective integration into the institution in all its segments.
\end{abstract}

KEYWORDS Inclusive action, quota system, social inclusion, public policies, university.

* Este artigo foi finalista na categoria Mestre da $3^{a}$ edição do Prêmio Políticas Públicas e Equidade: avanços práticos, promovido pelo Centro de Estudos em Administração Pública e Governo da Fundação Getulio Vargas de São Paulo, com apoio da Fundação Ford. 


\section{INTRODUÇÃO}

O presente artigo aborda a política de cotas nas universidades brasileiras, entendida como uma ação afirmativa ${ }^{1}$ que tem por objetivo a inclusão de negros oriundos de escolas públicas, por meio das cotas raciais. Implementada pioneiramente em 2003 pela Universidade Estadual do Rio de Janeiro (UERJ), foi seguida pela Universidade Estadual do Norte Fluminense (UENF), ambas no âmbito estadual, e, em 2004, pela Universidade de Brasília (UnB), no âmbito federal.

A iniciativa do governo do Rio de Janeiro e da UnB desencadeou a discussão efetiva sobre a implantação e a posterior implementação de ações afirmativas de cotas nas universidades públicas. Conforme estudo realizado pela Educafro (2010), esse número aumentou para mais de 150 instituições de ensino superior públicas a adotarem a política, afora outras que se encontram em processo de aprovação legal. Os motivos para a criação da política de cotas nas universidades são destacados pela Secretaria Especial de Políticas para a Promoção da Igualdade Racial (SEPPIR), a qual defende que as entidades públicas de ensino superior não podem ser um espaço das elites, e isso fica caracterizado quando os estudantes do ensino privado apresentam melhores condições de inserção na universidade pública, e os alunos de ensino médio provenientes das escolas públicas não obtêm o desempenho necessário para ingressar no ensino público superior, resignando-se, assim, às universidades privadas (SANTOS, 2008). Com relação aos docentes, o estudo de Carvalho (2005b) apontou que, de 1.500 professores da UnB, somente 15 (1\%) eram negros. Dados do IBGE (2010) também expressam essa exclusão ao informarem sobre a inserção no ensino superior brasileiro, pois $62,6 \%$ dos estudantes são brancos, 28,2\% são pretos e 31,8 \% pardos; ao considerar a conclusão da graduação, a diferença fica ainda mais evidente: 15\% dos formados são brancos, 4,7\% são pretos e 5,3\% são pardos.

Nesse sentido, o propósito do presente estudo foi investigar se a ação afirmativa de cotas raciais implementada na Universidade Federal do Rio Grande do Sul (UFRGS) é efetivamente inclusiva, o que justificaria, assim, sua criação e existência enquanto política pública. Para tanto, buscou-se identificar o contexto histórico em que ela se deu, bem como conhecer o entendimento e a avaliação de estudantes cotistas autodeclarados ${ }^{2}$ negros da UFRGS sobre o processo de ações afirmativas de cotas. A contribuição da pesquisa reside na investigação e na produção de elementos que possam subsidiar a análise da eficácia das ações de inclusão, nas universidades públicas brasileiras, de estudantes negros que concluíram o ensino fundamental e o médio em escolas públicas, bem como auxiliar na identificação de possíveis modificações e adequações necessárias à sua melhoria.

Para a pesquisa empírica, a coleta de dados foi realizada na UFRGS, utilizando as seguintes fontes: pesquisa documental; participação em eventos e comissões na instituição de ensino atinentes à temática investigada; entrevistas com servidores da universidade e alunos cotistas autodeclarados negros ingressantes a partir de março de 2008. A análise dos dados foi feita a partir da triangulação dos elementos obtidos nas diversas fontes investigadas. Especialmente nas entrevistas dos alunos utilizou-se a categorização, tendo como foco as questões norteadoras da investigação.

\section{AS COTAS ENQUANTO AÇÕES AFIRMATIVAS}

Segundo Gomes (2001, p. 6), as ações afirmativas "consistem em políticas públicas (e também privadas) voltadas à concretização do princípio constitucional da igualdade material e à neutrali- 
zação dos efeitos da discriminação racial, de gênero, de idade, de origem nacional e de compleição física". Em países com longo passado de escravidão, como o Brasil, mesmo que tenham sido instituídas disposições normativas constitucionais e legais para grupos sociais historicamente discriminados, com o passar dos anos a situação pouco mudou. Para o citado autor, a legislação não se faz acontecer: é preciso ação e implementação, pois os dispositivos legais não atendem às necessidades dos grupos discriminados, uma vez que as políticas governamentais são antidiscriminatórias e baseadas em leis de conteúdo meramente proibitivo. A discriminação é proibida legalmente; porém, é necessário que aconteça uma mudança cultural, pois o preconceito racial evidencia-se através da história e dos costumes transmitidos de geração para geração. Portanto, para que isso aconteça, "não basta proibir, é preciso também promover, tornando rotineira a observância dos princípios da diversidade e do pluralismo" (GOMES, 2003, p. 29).

Dessa forma, as ações afirmativas podem ser concebidas como ações de incentivo e suporte para determinados grupos de pessoas, que venham de alguma forma garantir a igualdade de oportunidades e de tratamento. Tais ações podem ser tomadas ou determinadas pelo Estado, bem como por instituições da sociedade civil que tenham autonomia para tomar decisões com relação às suas normas internas, tais como partidos políticos, sindicatos, centrais sindicais, escolas, igrejas, instituições privadas e mesmo as universidades públicas. Essas ações podem ter um caráter temporário ou permanente, dependendo das normas pelas quais são regidas. Tais dispositivos ensejariam oportunidades de acesso ao ensino, emprego, distribuição de renda, socialização, e, dessa forma, maiores chances de proporcionar caminhos diferentes da trajetória social habitual, com melhores oportunidades de mobilidade social.
No contexto educacional, Heinen (2008) afirma que as ações afirmativas são instrumento importante na promoção da educação e tema atual de profundos debates. Constata-se a necessidade de ações afirmativas no ensino a partir da evidência de que a formação superior atinge uma parcela muito restrita da população brasileira, dadas as grandes desigualdades sociais vigentes. Contudo, assinala Moehlecke (2004), a utilização de políticas raciais não equaciona a desigualdade de raça e classe existente no Brasil, sendo imprescindível aliar políticas sociais e, especialmente, a expansão e melhoria na educação básica brasileira para que seja alcançada a efetividade pretendida. Morche (2010) dimensiona que a busca de metas mais audaciosas de ampliação do acesso e inclusão no ensino superior passa pela melhora de qualidade do ensino médio, pois avalia que há diminuição de seu crescimento e qualidade.

Tais considerações explicitam que são necessárias ações mais amplas que incidam para garantir igualdade de oportunidades e mudar a ideia vigente na sociedade de que há supremacia e subordinação entre raças e gêneros. As ações afirmativas direcionadas principalmente ao ensino público serviriam de incentivo às gerações mais jovens, integrantes de grupos "minoritários", que

[...] invariavelmente assistem ao bloqueio de seu potencial de inventividade, de criação e de motivação ao aprimoramento e ao crescimento individual, vítimas das sutilezas de um sistema jurídico, político, econômico e social concebido para mantê-los em situação de excluídos (GOMES, 2003, p. 32).

Conforme Vieira (2003), a ação afirmativa no ensino superior é vista como uma ação voltada para o combate à desigualdade racial. É uma forma de equilibrar a população negra com a branca no que diz respeito aos índices sociais, principalmente educação, habitação e distribuição salarial. Por meio dela, a população negra poderá ser, de 
certo modo, compensada por meio da correção de uma situação de desvantagem que lhe foi imposta historicamente; e assim haverá a "promoção de uma sociedade mais democrática, a qual não pode ser atingida sem a igualdade" (VIEIRA, 2003, p. 86).

\section{PERCURSO INVESTIGATIVO}

Para responder à questão de pesquisa proposta pela pesquisadora - a política de cotas na Universidade Federal do Rio Grande do Sul configura-se como uma efetiva ação afirmativa para a inclusão de alunos negros egressos de escolas públicas no ensino superior? -, procedeu-se a uma investigação quanti-qualitativa, de característica exploratória e descritiva.

A pesquisa foi realizada em três momentos distintos, porém complementares, a saber: pesquisa bibliográfica e documental, participação em atividades na instituição e entrevista com servidores e com alunos cotistas autodeclarados negros da instituição de ensino. Tal processo compreende o período de julho de 2009 a outubro de 2010. A pesquisa documental foi realizada a partir de contatos e visitas institucionais realizados na UFRGS para a busca de informações, principalmente com relação ao inicio do processo de implantação e, posteriormente, ao de implementação da Política de Ações Afirmativas na instituição.

$\mathrm{Na}$ intenção de ampliar os dados encontrados, procedeu-se ao segundo momento, que consistiu na participação em eventos científicos realizados pela e na instituição pesquisada, atinentes ao tema da pesquisa, como, por exemplo: Seminário Diversidade na Universidade: A Questão da Negritude e I Seminário de Ações Afirmativas.

Já o contato com servidores para a ampliação das fontes secundárias pesquisadas e as entrevistas com os alunos cotistas autodeclarados negros remete ao terceiro momento da investigação. Os discentes foram convidados por meio de mensagem eletrônica para participarem da pesquisa, a partir de listagem obtida pelo pesquisador, contabilizando mais de 100 contatos; destes, 10 alunos demonstraram interesse em participar da pesquisa e, após consentimento formal, foi concedida entrevista pessoal. Portanto, foram realizadas 10 entrevistas face a face, que foram registradas com o uso de gravador digital e armazenadas em arquivos digitalizados. Os principais temas presentes nas entrevistas são os seguintes: os motivos que levaram o estudante a escolher a política de cotas para ingresso na universidade; sua apreciação sobre o convívio acadêmico; sua percepção da existência ou não de discriminação na universidade; seu conhecimento de programas internos que auxiliam na permanência do cotista na universidade; e sua identificação como cotista.

O método utilizado para a análise dos dados foi a técnica de triangulação. Nessa técnica, todos os dados coletados são devidamente organizados, entrelaçados e interpretados pelo pesquisador, apoiado nos fundamentos teóricos. Segundo Triviños (1999), a técnica da triangulação possibilita o máximo aprofundamento da descrição, da explicação e da compreensão do foco em estudo. Isso porque um fenômeno social não pode ser concebido de forma isolada, sem considerar as raízes históricas, os significados culturais e as vinculações estreitas e essenciais com sua realidade social.

\section{CONTEXTO DA INSTITUIÇÃO ESTUDADA}

$\mathrm{Na}$ Universidade Federal do Rio Grande do Sul, as discussões sobre as ações afirmativas de cotas se iniciaram oficialmente em meados de junho de 2004. O primeiro debate aconteceu no auditório da Faculdade de Educação e contou com a par- 
ticipação especial do antropólogo José Jorge de Carvalho, professor e mentor do mesmo projeto na UnB.

Em novembro de 2006, o então reitor da UFRGS, professor José Carlos Ferraz Hennemann, designou, pela Portaria no 3.222, de 3 de novembro de 2006, uma Comissão Especial para elaborar uma proposta de implantação do programa de ações afirmativas na UFRGS, a qual seria posteriormente submetida ao Conselho Universitário. O programa foi aprovado em junho 2007 e regulamentado pela Decisão no 134/2007 do Conselho Universitário, por um período de cinco anos, e atende a população de estudantes de escolas públicas, negros e indígenas (UFRGS-CONSUN, 2007).

O sistema de cotas na UFRGS se dá da seguinte maneira: são reservados 30\% do total das vagas para alunos oriundos de escolas públicas; e, dessas, a metade é destinada a alunos autodeclarados negros, que também devem ter obtido sua escolaridade na rede pública. Os alunos oriundos de escolas públicas deverão ter cursado no mínimo $50 \%$ do ensino fundamental e $100 \%$ do ensino médio nessas escolas. Nesse programa, todos os candidatos à reserva de vagas prestam as mesmas provas no vestibular e têm um mínimo de acertos necessários à classificação (uma nota de corte) de acordo com o curso escolhido. Os melhores colocados no vestibular ocupam $70 \%$ das vagas (cotistas e não cotistas). Para preencher os 30\% restantes, a universidade seleciona os candidatos inscritos como cotistas com as melhores médias. A metade dessas vagas (15\%) é ocupada por alunos de escolas públicas que tenham obtido as melhores médias; e a outra metade (15\%), pelos estudantes autodeclarados negros, também com as melhores médias. Caso não haja esses candidatos dentro dos pré-classificados no concurso, as vagas voltam ao acesso universal.

Aos candidatos indígenas, foram destinadas dez vagas extras a partir de 2008, número que pode ser alterado de acordo com a demanda. O programa passa por avaliações contínuas, e foram instituídas duas comissões para seu acompanhamento: a Comissão de Acesso e Acompanhamento do Estudante Indígena; e a Comissão de Acompanhamento do Programa de Ações Afirmativas, esta última também com a função de promover as condições para que o estudante de baixa renda tenha a possibilidade de se manter no seu curso até a formatura.

A UFRGS, até dezembro de 2010, contava com 4.190 alunos cotistas. Desse total, 773 são autodeclarados negros, e 3.417 são alunos oriundos de escolas públicas (UFRGS-COPERSE, 2010). Os negros não preenchem todas as vagas destinadas às cotas raciais, que são 15\% do total de vagas em cada curso. Contrariamente aos candidatos autodeclarados negros, que não preenchem as vagas que lhes são destinadas, os candidatos oriundos de escolas públicas preenchem praticamente todo o percentual destinado (15\%), mais as vagas que não são preenchidas pelos autodeclarados negros, ocupando, dessa maneira, mais de 100\% das cotas sociais. Em 2008, os alunos oriundos de escolas públicas preencheram 153\% das cotas; em 2009, esse percentual aumentou para 163\%; e em 2010, teve uma queda de 2 pontos percentuais com relação a 2009 , totalizando $161 \%$, revelando disparidade entre as formas de ocupação das vagas para os cotistas na instituição.

O total de vagas oferecidas para cotistas durante o período 2008-2010 foi de 4.284, sendo 50\% para cada modalidade de cota. Foram preenchidas 773 vagas pelos autodeclarados negros, o que representa 36\% do total oferecido para cotas raciais; os candidatos oriundos de escolas públicas preencheram 3.417 vagas, o que representa 159\% das 2.142 vagas. Mesmo os candidatos às cotas tendo preenchido praticamente todas as vagas, 94 destas foram direcionadas ao acesso universal, por não terem sido preenchidas por cotistas: em 2008, 19 vagas; em 2009, 26 vagas; e em 2010, 


\section{MARIA CRISTINA LUNARDI KERN E DENISE MACEDO ZILIOTTO}

49 vagas destinadas às cotas foram preenchidas por candidatos que tiveram acesso universal à universidade, o que pode ser visualizado na Tabela 1, abaixo:

Tabela 1 - Número de vagas oferecidas e preenchidas por modalidade de cota, de março de 2008 a março de 2010

\begin{tabular}{|c|c|c|c|c|c|c|}
\hline \multirow[b]{4}{*}{ Ano de ingresso } & \multicolumn{4}{|c|}{ MODALIDADE DE COTAS } & \multirow{3}{*}{\multicolumn{2}{|c|}{$\begin{array}{c}\text { TOTAL GERAL } \\
2008-2009-2010\end{array}$}} \\
\hline & AUTODE & ADOS & ESCOLAS & BLICAS & & \\
\hline & \multicolumn{4}{|c|}{ NÚMERO DE VAGAS } & & \\
\hline & Oferecidas & Preenchidas & Oferecidas & Preenchidas & Oferecidas & Preenchidas \\
\hline 2008 & 667 & 295 & 667 & 1.020 & 1.334 & 1.315 \\
\hline 2009 & 704 & 231 & 704 & 1.151 & 1.408 & 1.382 \\
\hline 2010 & 771 & 247 & 771 & 1.246 & 1.542 & 1.493 \\
\hline $\begin{array}{l}\text { Total por } \\
\text { modalidade de cota }\end{array}$ & 2.142 & 773 & 2.142 & 3.417 & 4.284 & 4.190 \\
\hline
\end{tabular}

Fonte: UFRGS, COPERSE, 2010. Tabela construída pela autora.

Em 2010, a UFRGS contou com 75 cursos de graduação; e de 2008 a 2010, o número total de ingressos via cotas foi de 4.190 alunos. Em 2008, 14 de 69 cursos com possibilidades de ingresso não tiveram preenchidas as vagas destinadas a candidatos autodeclarados negros; somente cinco cursos preencheram 100\% das vagas destinadas a esses alunos, sendo três destes noturnos; e 21 cursos tiveram $50 \%$ ou mais das vagas destinadas a autodeclarados negros preenchidas, sendo seis noturnos. Em 2009, de 75 possibilidades, 14 cursos não tiveram as vagas preenchidas; cinco cursos preencheram 100\% das vagas, sendo três destes cursos noturnos; e 12 cursos preencheram $50 \%$ ou mais, sendo cinco noturnos. E em 2010, de 86 possibilidades, 29 cursos não tiveram as vagas preenchidas pelos candidatos autodeclarados negros; as vagas oferecidas foram preenchidas em
$100 \%$ em apenas três cursos, todos noturnos; e $50 \%$ ou mais das vagas oferecidas a autodeclarados negros foram preenchidas em 16 cursos, quatro destes noturnos. (UFRGS-COPERSE, 2010).

Diante desse quadro, o não preenchimento total das vagas oferecidas aos autodeclarados negros, pode-se constatar, conforme Morche (2010), que "As Políticas Afirmativas vêm garantindo maior equidade e inclusão social no Ensino Superior, contudo, o impacto quantitativo ainda é insuficiente para garantir maior democratização do acesso ao ES" (p. 5).

Segundo análise feita pela UFRGS do desempenho dos alunos cotistas e não cotistas que ingressaram na universidade em 2008 em cinco cursos de diferentes áreas, no geral, indica que os alunos que entraram pelo acesso universal - ou seja, sem a necessidade de reserva de vagas - obtiveram, no 
primeiro semestre, um desempenho acadêmico de $86,1 \%$; já o desempenho dos ingressantes em cotas do ensino público foi de $72,5 \%$; e o dos cotistas negros, de $71,5 \%$. Fica, então, demonstrado que o índice de aproveitamento dos alunos cotistas foi significativo, levando-se em consideração o nível sócio econômico dos negros, que é mais baixo, o que, consequentemente, afeta o nível de escolaridade, o qual torna-se menor em relação ao dos brancos (CARVALHO, 2005a). Constatou-se, ainda, que, no início, o desempenho dos cotistas é mais baixo; porém, no decorrer do primeiro e do segundo semestre de 2008, houve uma melhora e até uma superação desses cotistas em relação aos demais estudantes (PIRES, 2009).

Ainda segundo essa análise, o pior desempenho dos cotistas se deu em engenharia civil, com o aproveitamento dos cotistas negros inferior a $50 \%$ (os alunos de ingresso universal superaram os $60 \%$ ). Já o melhor resultado foi obtido no curso noturno de direito, em que os alunos de escolas públicas empataram com os do acesso universal; e os negros superaram os dois grupos, com 98\% de aproveitamento (PIRES, 2009). Tais dados apontam que os cursos que preencheram $100 \%$ das vagas, na maioria, e não por acaso, são noturnos, o que sugere que esses alunos estejam comprometidos com outra atividade durante o dia. Os estudantes que tiveram acesso à universidade inicialmente não têm um bom aproveitamento; porém, no decorrer do curso, conseguem superar suas dificuldades e até mesmo seus colegas que não entraram por cotas.

Para Oliven (2009, p. 10), a UFRGS, ao adotar o sistema de cotas, demonstrou seu empenho em respeitar os direitos humanos e reconhecer a diversidade com justiça e equidade, considerando que "enquanto as imensas desigualdades socioeconômicas, educacionais e raciais nos empobrecem, a diversidade nos enriquece". Segundo o autor, em um país como o Brasil, que é uma das maiores economias do mundo - porém muito injusto socialmente -, tais atitudes ganham um significado simbólico muito grande.

\section{O DISCURSO DOS COTISTAS}

As entrevistas com os alunos cotistas tiveram a intenção de poder aprofundar informações coletadas nos outros dois momentos da investigação, bem como conhecer a visão dos discentes sobre o processo que estão vivenciando. Após serem transcritas, as entrevistas foram analisadas para o reconhecimento de categorias, a partir do aplicativo Qualisoft, estabelecendo-se as seguintes unidades para desenvolvimento das questões trazidas pelos entrevistados: percurso do aluno cotista; racismo e discriminação; cotas enquanto ação afirmativa; acolhimento na universidade e efetividade do processo inclusivo. Para esta análise foram realizadas dez entrevistas com alunos de diferentes cursos: dois do curso de educação física (Kaleo e Josephine), um de filosofia (Amir), um de ciências econômicas (Joyce), um de ciências atuariais (Perla), um de psicologia (Talita), um de medicina veterinária (Júlia), um de biologia (Poliana), um de serviço social (Talassa) e um de letras (Raul); dos dez alunos, dois são do sexo masculino e oito do sexo feminino; a faixa etária varia de 18 a 33 anos. Na reprodução das falas foram utilizados codinomes para preservar a identidade dos entrevistados neste percurso investigativo.

\section{PERCURSO ESCOLAR DO ALUNO COTISTA}

Os entrevistados referem que as escolas públicas, de um modo geral, estão com sérios problemas para atender a necessidade de aprendizagem dos alunos, principalmente no final do ensino médio, quando estão próximos a prestarem um concurso vestibular. Classificaram o ensino fundamental 
como fraco, dois entrevistados; como muito fraco, três; de regular a bom, dois; como sendo bom, dois; e muito bom, somente um dos entrevistados. O ensino médio foi classificado como fraco por um dos entrevistados; como muito fraco, por quatro; de regular a bom, por dois; como bom, por três entrevistados, e nenhum dos entrevistados valora o ensino como sendo muito bom.

Um fator apontado por cinco entrevistados como prejudicial no ensino foi a postura do professor diante das classes. Alguns dizem que o professor faz a diferença em sala de aula, independentemente de a escola ter uma estrutura física adequada. Alegam que os professores parecem desestimulados com a profissão escolhida, consequentemente, não estimulam o aluno a buscar o aprendizado, pois as aulas acabam ficando monótonas e sem atrativos, e outros professores demonstram não ter experiência e a didática fica a desejar; o salário defasado é um agravante nas condições físicas e psíquicas do professor.

Contudo, existe a consideração de que há professores no ensino público que, apesar das condições precárias da escola, se esforçam para atender e estimular a aprendizagem dos alunos:

[...] tem profissionais de escola pública que se reviram e tiram até do bolso para, de certa forma, suprir aquelas carências que os alunos das escolas públicas têm (KALEO).

Ao fazerem uma análise sobre a possibilidade de ingressarem na universidade sem a política de cotas, seis alunos foram enfáticos ao responder que não teriam ingressado; dois tiveram dúvidas e dois acreditam que teriam ingressado independentemente das cotas. Os motivos que concorreram para a escolha dos cursos para os quais ingressaram na universidade foram os mais variados; porém, nota-se que a afinidade com a área foi fundamental para a escolha.

Quanto ao aproveitamento desde o início do curso, dos dez alunos entrevistados, apenas dois não tiveram reprovação; quatro foram reprovados em uma disciplina; um foi reprovado em duas disciplinas e três foram reprovados entre cinco e sete disciplinas. Os motivos para essas reprovações foram, principalmente, dificuldade nas ciências exatas, sendo cálculo a principal disciplina apontada, bem como física, matemática, lógica e álgebra; também tiveram reprovação os alunos que precisavam trabalhar e/ou moravam em outra cidade, ficando, portanto, com muito pouco tempo disponível para o estudo; e também por motivo de doença do pai ou da mãe.

Autores como Schwartzman (2008) e Carvalho (2005a) discordam em relação à implementação das ações afirmativas de cotas, mas concordam que os alunos do ensino fundamental e médio público têm maiores dificuldades de acesso à universidade por meio do vestibular tradicional, pela defasagem do ensino nas instituições públicas. Essa situação fica evidente quando, dos dez entrevistados, seis afirmam categoricamente que não teriam ingressado na universidade se não fosse a política de cotas, e dois ficam em dúvida quanto à possibilidade de ingressarem sem as cotas. Também se pode constatar a dificuldade que os entrevistados enfrentaram no início dos cursos com as disciplinas onde se faz necessária a base do ensino, principalmente nas ciências exatas, em que apontam dificuldades desde o ensino fundamental e médio. Dentre o grupo de entrevistados, um dos alunos estudou em escola particular e outro em escola pública bastante diferenciada, e puderam fazer a comparação entre as instituições, com condições físicas e com recursos humanos muito bons. Na verdade, não é só o fato de a escola ser particular, mas os recursos que cada escola tem, pois nas escolas públicas com recursos adequados o ensino também é muito bom, conforme relato de alunos que passaram por essa experiência. O problema é que são poucas as escolas públicas com bons ou ótimos recursos, o que pode 
determinar a escolha feita da modalidade para prestar vestibular como possibilidade de ingresso na universidade.

\section{RACISMO E DISCRIMINAÇÃo}

A relevância desta categoria, que aborda o racismo e a discriminação, para o objeto da pesquisa, é significativa. A pergunta que originou os temas destacados, inicialmente, não relacionou as duas questões, pois a indagação centrava-se na discriminação. Contudo, a associação com o racismo emergiu - por vezes mais explícita, em outras de maneira sutil - como decorrência das considerações que eram trazidas acerca da discriminação. Os sujeitos da pesquisa, quando perguntados de forma direta sobre a discriminação, dizem não terem experimentado tal situação na universidade:

Eu não sinto, por que lá tem muitos grupinhos, sabe? Então se eles olham torto para ti, é porque eles não gostam de ti, independente de eu ser negra ou branca, é isso sabe? Eu também não gosto de muita gente que estuda lá, eu acho que é muito... um quer ser melhor que o outro. Mas eu não senti nada em relação a minha cor. Tudo é assim, eu não gosto de ti e pronto, nada pessoal, nada relacionado a cor (JÚLIA).

Porém, em alguns momentos, quando a pergunta seguinte é feita - onde é indagada a possibilidade de terem conhecimento sobre alguém que tenha tido tal experiência - nota-se que as respostas mudam. Por exemplo, admitem a ocorrência, mesmo de maneira vaga, ao dizerem que 'ouvem falar, mas que não falaram diretamente para eles':

Não. Eu vejo que as pessoas falam: Ah, cotista, por quê? Eu acho que então a cota quer dizer que o negro é burro, não tem condições de passar? Mas ninguém nunca falou diretamente pras pessoas, eles falam assim... de um modo geral, mas nunca chegaram em mim e falaram ou nunca soube isso também por um dos colegas meus (JOYCE).

Ou, ainda, quando perguntados se conhecem alguém que tenha sofrido algum tipo de discriminação, mesmo tendo respondido anteriormente não ter sofrido nenhum tipo de discriminação, referem ao seu próprio caso:

Na Unidade de Ensino, na Filosofia, e foi explícito, não teve nem disfarce. No primeiro encontro de alunos, um grupo de pessoas que defendia uma não utilização das cotas no ingresso na UFRGS, foi bastante enfático na insatisfação deles com ingresso de cotistas. Mas conversaram comigo assim, na boa, foram tranquilos, mas foram bem enfáticos, eles não esconderam o fato de não gostar da política de cotas. Mas eles chegaram a te constranger neste momento? Tentaram, mas eu acredito que me saí bem. Porque eu debochei, dei risada e disse que não ia mudar nada, que eles poderiam falar até dizer: Chega! que eu já estava aqui mesmo. Eu acredito que isto é uma forma de discriminar, o jeito de... por mais tranquilo que seja, eles deixaram muito claro que na visão deles isto é errado, a política de cotas, e havia uma separação de quem é cotista e de quem não era... só neste evento inicial (AMIR).

Existe também a percepção clara da discriminação velada, como identificam os entrevistados:

[Silêncio] Pois é, aí é que está... eu não posso dizer que fui discriminada por ninguém, mas tem uma coisa que é meio séria, meio velada, sabe? De que o teu lugar é outro. Então tem umas mensagens subliminares que são passadas,... por muito tempo... mas é muito assim dos colegas, da relação dos colegas mesmo, enfim... eu não sei explicar com palavras, mas vou te dar um exemplo: quando eu entrei eu tinha 16 (anos) e isso era algo que chamava muito a atenção das pessoas: Como assim, tu tens 16 anos? E eu tinha uma outra colega que também tinha 16, uma outra menina. Só que esta outra menina não era cotista, então por diversas vezes muitos dos meus colegas, principalmente esses que se põem claramente contra, vinham comentar comigo ou com alguém que tava comigo: Nossa, como a menina lá é inteligente, a outra não é? Passar na UFRGS com 16 
anos, nossa... é tão difícil ver alguém assim. E sempre dando a noção de que ela era a única que tinha feito isso, então a mensagem era basicamente que: Bom, ela passou na UFRGS porque passou sem cotas e eu passei nas cotas, é diferente. É um outro patamar. E essa mensagem e outras são passadas frequentemente assim, então a minha turma, por exemplo, era a turma dos lados, então tinha não cotistas pra lá e cotistas pra cá basicamente. E isso nunca foi dito, nunca foi combinado: Bom, eu vou sentar pra lá porque eu não me misturo. E na verdade quando eu entrei na faculdade eu sentava do lado dos não cotistas, porque eu não me ligava dessas coisas assim, e isso nunca foi dito, nunca foi trabalhado, nunca foi expresso, mas são coisas que vão se formando e vão acontecendo que impedem que dali a pouco uma pessoa não cotista que se dá muito bem comigo, não possa sentar do meu lado, porque é o lado dos cotistas ou que eu não possa passar pra lá. Mas é uma coisa que nunca foi dita, nunca foi expressa, mas acontece e é claro (TALITA).

Um entrevistado também se refere a uma situação ocorrida com ele em outro momento da sua formação escolar, que aqui se alude esta fala para identificar que estes alunos possivelmente já sofreram discriminação no percurso da escolarização, mostrando a dimensão que isto pode implicar no âmbito educativo:

Já sofri discriminação racial no colégio privado, quando eu estudei na segunda série. Isso de outro colega meu, que fez um comentário racista e que eu, de certa forma, já estava preparado para isto, por isso... pela minha educação.Na minha família já disseram: Oh, pode acontecer certas situações e tu tem que agir de certa forma. Se te chamarem de... desculpe a palavra, de preto sujo, tu simplesmente olha e diz: Ta e daí que eu sou preto? E aí, qual é o problema? Eu não tenho fome igual a ti, não tenho vontade de ir ao banheiro igual a ti? (risos) Eu não choro igual a ti? Foi exatamente isso que eu respondi... nunca mais sofri nenhum tipo de preconceito. Claro, a gente... às vezes a gente nota olhares... olhares que dizem mais que um monte de palavras. Só que olhares eu já senti tantos olhares, que eu já nem lembro mais das pessoas. [...] Nada, aqui não. Nem olhares, eu acho que nem olhares assim, que eu me lembre agora não, nem olhares (KALEO).

Quando perguntados se têm problema em se identificarem como cotistas na universidade, a resposta de cinco alunos foi negativa. Para alguns, inclusive, é motivo de orgulho, pois estão fazendo parte de um momento histórico. Contarão para seus descendentes que fizeram parte dessa conquista e, principalmente, vão estimular amigos e parentes a terem a ambição e verem que é possível entrar numa universidade pública, gratuita e de qualidade.

Olha, eu não sinto nenhum constrangimento, eu sinto até orgulho sabe?...é um fato histórico, isso é histórico. Eu faço parte da primeira... Quando eu for velho, independente se eu for rico ou pobre, eu vou dizer para o meu neto assim: "Guri, eu fiz parte da primeira turma de cotistas de uma faculdade, de uma universidade, uma universidade federal. E isso é fato de orgulho para mim, e tem que ser fato de orgulho para ti. Eu como referência para ti, dizendo para o meu neto, por exemplo, e que ele tem que estudar, e isso é uma motivação... eu vi parentes meus vendo que eu entrei para a universidade federal, me tendo como espelho e fazendo um curso pré-vestibular, popular também, ou estudando em casa, para entrar numa universidade federal, sabe? (KALEO).

Além do orgulho que o entrevistado sente em fazer parte deste momento histórico, acrescenta que o fato de ser oriundo de escola pública não o impede de ser um ótimo aluno, tendo um desempenho superior a de alunos advindos de escolas particulares:

E esse negócio de que: Ah, eles vão ter um desempenho pior dentro da universidade, porque eles têm um desempenho menor, porque eles vieram de escola pública e escola pública é mais fraca, isso é um absurdo! Porque tem colegas meus que vieram de colégios, desculpe falar o nome dos colégios, mas do 
Colégio Anchieta, do Farroupilha, que eu tenho um currículo melhor do que o deles aqui dentro, sabe? Eu tenho mais conceito A do que eles. Eu não sou o melhor aluno da minha turma, não sou o melhor, mas sou muito melhor do que muita gente aqui dentro. Eu sei disso, eu confio em mim (KALEO).

Contrariamente, outros entrevistados se sentem ou se sentiram, em um primeiro momento, constrangidos em se identificarem como cotistas:

Racial sim, sinceramente eu fico. Porque daí assim: como eu sei que nesta questão de mérito parece que tem uma ideia... por ter o ingresso assim... seria... ah a pessoa tem menos... sei lá... menos... não posso falar mais burra, mas menos conhecimento. Daí assumindo que eu sou cotista racial parece que... sei lá... ah, ela é mais burra, alguma coisa assim. Essa é a impressão que me passa se eu falar (POLIANA).

Talita diz não ter problema em se identificar, porém sente a diferença de classe, trazendo dimensões mais amplas da questão:

Não, porque na verdade tem isso assim... até surgirem as cotas não tinham negros na Psicologia, então é uma coisa meio óbvia, mas nunca me perguntaram, nunca foi preciso... todo mundo é igual. Só que eu acho que às vezes até por se partir deste princípio, tu acaba ignorando algumas diferenças que importam, sabe? Por exemplo: esta divisão de lados não tem só a ver com cotas, tem a ver com uma diferença social também. Até que ponto ele se propõe a viver de igual para igual com pessoas de outro nível, e a gente também? Porque eu mesma tive muita dificuldade em... bom... tá ali com pessoas de outro nível social e que... bom, faziam um milhão de coisas que eu não fazia e que ganharam carro porque passaram no vestibular. Bom, eu não ganhei nada, então eu tinha 16 anos, eu era bem imatura, aquilo me revoltava muitas vezes, sabe? E eu acho que tem muito disso, dessas diferenças que existem e estão ali, interferem nas relações, mas que muitas vezes são ignoradas também (TALITA).

Os entrevistados não referem explicitamen- te que a discriminação e o racismo ocorrem na universidade. Porém, percebe-se que ela ocorre, mesmo quando dizem não sentir a discriminação diretamente, pois há menção à ocorrência da discriminação e do preconceito racial, seja claramente identificado ou de forma velada. Foram relatadas ocorrências explícitas destes momentos na universidade, por fatos ocorridos diretamente com os entrevistados ou por fatos ocorridos com alunos de outros cursos e também com cotistas que ingressaram por outra modalidade, como os indígenas. Assim como um relato de discriminação ocorrida fora desta, mas que aconteceu durante o percurso escolar do entrevistado.

Outros entrevistados orgulham-se por estarem fazendo parte deste momento histórico de políticas públicas implementadas no Brasil e que servirão de exemplo para familiares que ainda não tentaram ingressar na universidade pública, bem como para futuras gerações. Isso vem afirmar o que nos diz Gomes (2003), que a política de ações afirmativas é a oportunidade de transformar o comportamento e a mentalidade do povo, de tal forma que as próximas gerações de grupos minoritários tenham condições de almejar um futuro melhor, com incentivo para o aprimoramento e crescimento individual.

\section{COTAS ENQUANTO AÇÃO AFIRMATIVA}

Dos dez alunos entrevistados, três dizem desconhecer o verdadeiro objetivo da política de cotas, referindo-se a ela de maneira vaga. Os demais, apesar de afirmarem conhecer a política, as manifestações sugerem que o entendimento é reduzido, pouco substanciado. A informação mais presente para os entrevistados se refere aos percentuais destinados. Secundariamente, algo sobre o objetivo de tal política:

Sim, é uma política, a princípio, para dar oportunidades e tentar equiparar uma diferença de 
classes e racial históricas. Então, a princípio, seria para reduzir uma desigualdade histórica e depois seria, ou será, revisto o projeto para ver se é necessário continuar, se de alguma forma foi equiparado esta desigualdade histórica (AMIR).

O principal motivo apontado que os levou a ingressarem pela política de cotas foi a facilidade para o ingresso, porque o vestibular é classificado como muito difícil:

[...] ia facilitar bastante, o vestibular da UFRGS é muito difícil. E quando eu estava no terceiro ano, era uma correria, porque estudava de manhã, trabalhava a tarde, para pagar o cursinho que eu fazia de noite... mas sem cotas eu não teria entrado (JOYCE).

Os entrevistados indicam como motivo para ingressarem como cotistas o fato de terem desta forma uma chance a mais, uma oportunidade melhor; também justificam por se tratar de um direito legal e também porque acreditam que a política é necessária para que os negros possam alcançar um patamar melhor na sociedade:

[...] eu estava dentro do direito, e pelas cotas raciais eu sou... apesar de ter o meu pai branco e a minha mãe negra, eu já fui chamada de negrinha na rua, várias vezes, então eu me considero negra (JOSEPHINE).

Primeiro que é um direito legal... não que isso vá me fazer entrar, até porque eu vou ter que fazer uma prova e estudar assim como qualquer outra pessoa, e se eu não obtiver média, eu não vou entrar (RAUL).

Observou-se nessa categoria que, aos entrevistados cotistas autodeclarados negros que utilizaram o sistema de cotas para terem acesso à universidade pública, ainda falta conhecimento político do que essa iniciativa das universidades públicas representa de fato para essa camada da sociedade. Os entrevistados estão tendo acesso à universidade via cotas, porém com pouco conhecimento dessa política e do que ela de fato deve promover.

Também é possível observar a dificuldade vivida quando eles se referem à necessidade de trabalhar em horário em que não haja aulas, no ensino médio e no cursinho pré-vestibular, para terem acesso à meia bolsa que era disponibilizada pelo último. As entrevistas ainda possibilitam refletir sobre o fato de o vestibular não ter alcance para avaliar outras qualidades e potencialidades dos candidatos, pois os alunos cotistas demonstram, após o ingresso, que estas são estimuladas e trazem respostas positivas quanto ao aproveitamento desses alunos.

\section{O ACOLHIMENTO NA UNIVERSIDADE}

Dentre os entrevistados, quatro relataram que inicialmente tiveram um pouco de dificuldade em adaptar-se ao ritmo de estudo e também em acompanhar os conteúdos, principalmente os básicos. Referiram também sentirem-se receosos quanto ao acolhimento por parte dos colegas:

Meu ingresso... eu entrei meio receoso, questão de como eu vou ser recebido por ter entrado por cotas? Como eu vou ser recebido pelos meus colegas? Olha, tenho a dizer que sou muito bem recebido, fui muito bem recebido, nunca ouvi comentário de que... de colegas meus de que: Ah, tu é cotista. Nunca houve essa diferenciação, que eu ouvi dizer de doutores na TV que: Ah, mais isso aí vai haver essa diferenciação, então porque que tem cota, eles vão acabar sofrendo preconceito lá dentro (KALEO).

Então eu imaginava que ia ser uma coisa horrível assim, que eu ia ser tão discriminada aqui quanto naquele ônibus assim. Até porque cota racial tu carrega na cara né? Tu não tem muito como esconder (TALITA)

Os cotistas mencionaram a exigência que imaginaram antecipadamente que os professores teriam, exatamente por serem cotistas e oriundos 
de escolas públicas:

No início eu fiquei com um pouco de medo, né? Porque eu cheguei... e agora? Eu entrei por cotas e não vou saber, e os professores vão cobrar coisas e agora o que eu faço? Mas depois que eu fui acompanhando, pegando o ritmo da universidade, no primeiro semestre assim, não tive nenhum problema... meu desempenho é bom, não tenho maiores problemas e consigo acompanhar os conteúdos...(RAUL).

Manifestaram ainda que se sentiram incapazes de continuar, por terem tido reprovações no primeiro ou no segundo semestre; contudo, declaram ter sido tranquilo o momento de acolhida, quando interrogados diretamente sobre essa questão:

Eu me senti feliz, porque eu nunca participei de uma coisa tão grande, sabe?... eu me senti bem entrando na faculdade porque era uma oportunidade de eu ir além da onde a minha mãe foi, de onde eu estava, sabe? E consegui algo melhor para a minha vida... no geral eu me senti muito bem. Me senti realizada porque é um esforço meu, além das cotas, se eu não tivesse estudado eu não teria passado, independente de cotas. E eu me senti muito feliz, porque é uma coisa que eu consegui (JÚliA).

Contudo, ao falarem mais sobre este momento, indicam certa insegurança sobre sua efetiva inclusão:

[...] com respeito aos colegas. Eu até agora não sofri nenhuma discriminação, mas eu sei que existe, sei, eu não sofri, mas eu sei (POLIANA).

Eu nunca fui maltratada assim, por professor, funcionário, colega, nem ninguém, mas existe um consenso assim de que... bom, é um lugar inferior e de que tu entrou por um lugar inferior. Isso na visão da maioria dos meus colegas e mesmo de alguns professores. Então, como a gente foi a primeira turma, eu sentia muito isso nos professores, do tipo: "Bom, então me mostra a que tu veio", sabe? E enfim, eu acho que tem um pouco disso. Mas, eu nunca fui maltratada, teve sempre um cuidado muito grande (TALITA).

Ao serem questionados se vivenciaram alguma forma de discriminação, não houve referência direta, mas há menções que sugerem a ocorrência de discriminação velada:

Vários! Colegas, funcionários, professores da educação física, que é onde eu trabalho, e também colegas da filosofia. E também algumas pessoas vendo, abordando aspectos negativos, outras, aspectos positivos na implantação das cotas e sabendo que eu entrei pelas cotas. Não foram poucas vezes, aliás (AMIR).

Por colegas sim. Por conversas de rodas, com amigos. "Como é que tu entrastes aqui? Foi pela universal? Foi por qual modalidade de cota, se por escola pública ou se era pela cota racial. Não, eu dizia, entrei pelos dois". Algumas pessoas ficavam... faziam alguns comentários meio que... chatos, sabe? Mas eu sempre dava um corte. De qualquer forma eu entrei, estudei, estou aqui e vou para frente, não me interessa. Só que é difícil falar isso, né? (RAUL).

Nessa categoria, pode-se verificar que os alunos cotistas manifestaram ter vivenciado um bom acolhimento na universidade. Apesar de pesquisadores como Fry e Maggie (2004) e Schwartzman (2008), que se manifestam contrários às cotas raciais nas universidades por acreditarem que essa modalidade de ingresso causaria a segregação entre negros e brancos, pode-se constatar que nenhum dos entrevistados sentiu abertamente que a comunidade acadêmica esteja fazendo essa separação entre cotistas e não cotistas. Porém, como é característica da sociedade brasileira, alguns dos entrevistados relatam que há certo desconforto que gera insegurança na efetividade da sua inclusão. E isso transparece quando dizem "até agora não sofri nenhuma discriminação, mas eu sei que existe" ou "é um lugar inferior" e de que "tu entrou por um lugar inferior", ou quando o en- 
trevistado diz "até agora", o que denota que está esperando que a qualquer momento possa sofrer algum tipo de discriminação. Ferreira (2002) refere que os afrodescendentes têm até hoje uma forte tendência a incorporar a visão dominante do mundo branco, que é reconhecido como superior; ou porque percebe a discriminação vela$\mathrm{da}$, o racismo assimilacionista existente no povo brasileiro.

Porém, uma possibilidade de que esse sentimento se desfaça é quando percebem o seu aproveitamento, passado o primeiro momento de receio e insegurança, e após se apropriar da dinâmica da universidade, o que é expressivo na frase usada pela entrevistada Josephine: "Eu acho até que a gente não tem tanta diferença dos outros alunos, é normal"...

\section{A EFETIVIDADE DO PROCESSO INCLUSIVO}

Estão presentes questões que permitem perceber se o aluno cotista se sente incluído na universidade a partir de seu envolvimento em atividades acadêmicas no ensino, pesquisa ou extensão. Considerações a respeito da função inclusiva, por meio das cotas, para o acesso à educação superior e a avaliação feita por esses alunos da política de cotas também são atinentes a esta categoria.

Quanto à participação em atividades acadêmicas, os alunos têm participado principalmente em atividades de extensão, secundariamente em atividades de pesquisa e somente um aluno em monitoria no ensino. Na pesquisa, duas alunas estão envolvidas e três alunos ainda não participaram de atividades extra-acadêmicas, mas pretendem futuramente participar como bolsistas de iniciação científica. No momento, esses alunos têm algum tipo de bolsa ${ }^{3}$, disponibilizada pela UFRGS a alunos da graduação regularmente matriculados, o que lhes ocupa tempo considerável, 20 horas semanais, além das disciplinas cursadas, impedindo-os de participar de projetos e atividades nas áreas acadêmicas (ensino, pesquisa e extensão). Porém, eles manifestam conhecimento de que na universidade haveria oportunidades de atuarem numa das três áreas, em projetos ou atividades diretamente relacionadas ao seu curso, onde também há a possibilidade de remuneração.

As considerações dos alunos cotistas quanto ao fato de o ingresso por cotas estar cumprindo a sua função inclusiva de acesso à educação superior são positivas. Somente uma aluna faz uma análise divergente, pois acredita que esse processo não cumpre totalmente a função de incluir, uma vez que integrar a negritude no espaço acadêmico deveria fazer parte dessa inclusão:

Porque o que a gente tem é assim... a gente coloca negros dentro da universidade mas a gente não inclui eles realmente... como é que eu posso dizer... a gente não traz a realidade dos negros para a universidade, assim... não tem aquela troca. Por enquanto a gente ta recebendo informação, recebendo muita informação, só que a gente não tá... não sei se uma falta nossa... alguma coisa assim... mas a gente não tá colocando o que a gente sabe para as pessoas. Para ter a troca, para as pessoas entenderem melhor o processo de cotas e tudo mais. A cultura do negro e tudo que envolve, não tem essa troca aqui. Até nas Ações Afirmativas ${ }^{4}$ foi discutido isso, e tanto para negros como para índios está havendo o processo de branquear o aluno e não de fazer a troca de conhecimento (POLIANA).

Os demais alunos consideram que a política de cotas está conseguindo cumprir a sua função de incluir um número considerável de negros, pois atualmente se vê muito mais negro na universidade do que já se viu anteriormente. Percebem também que isso ocorre não só por serem negros, mas porque realmente não teriam acesso ao ensino público superior se não fosse por cotas. Avaliam que possuem uma condição financeira que não lhes possibilita ter uma educação básica boa, e alguns também não fizeram cursinhos pré-vestibulares; consequentemente, não teriam 
condições de concorrer em igualdade de condições com alunos que cresceram em uma classe social muito diferente da sua, com maiores possibilidades para enfrentar um concurso e ser bem-sucedidos:

Eu tenho percebido muito os alunos de origem negra na universidade, e pobres, pobres perdão... financeiramente falando, e eu sei que eles entraram por cotas, e eu sei que vários deles não teriam entrado se não fosse essa política. Então tem cumprido com sobras um papel, nem que seja momentâneo, paliativo... não sei até quando vai ficar essa política, mas tem ajudado (AMIR).

Alguns manifestaram também sua opinião quanto ao vestibular considerando-a uma forma injusta de acesso à universidade, em função das questões socioeconômicas e do ensino básico defasado, como visto anteriormente, mas também pela falta de incentivo familiar:

Porque eu acho que o vestibular é só uma porta assim né? Só um detalhe, não é a coisa mais importante da universidade. Então até sou contra, preferia como é nos Estados Unidos, que tu vai olhar os currículos, analisar se vale a pena ou não ajudar. Porque vestibular eu acho meio injusto, porque quem tem mais dinheiro, quem teve acesso a um ensino muito superior, colégios privados, então tem mais chance de passar do que pessoas que não conseguiram, que estudaram em colégio público, que não tiveram, muitas vezes, incentivo da família. Porque é mais fácil pra quem tem um pai e uma mãe médicos, prestar vestibular para Medicina, do que para quem tem um pai e uma mãe faxineiros, por exemplo. Então tem toda esta estrutura familiar, dos vizinhos, dos amigos (JOYCE).

Outro fato apontado para conceber o vestibular como uma forma injusta de acesso é que os alunos cotistas estão conseguindo comprovar que o ingresso nada tem a ver com o comprometimento dos alunos pós-ingresso, segundo os sujeitos da pesquisa. Os dados apontam que os cotistas têm conseguido ter um aproveitamento muito bom em relação aos não cotistas, quando não de superação, em alguns cursos.

No [curso pré-vestibular da cidade de Porto Alegre], que foi divulgado o desempenho dos cotistas e das pessoas do acesso universal, é praticamente o mesmo. Então aí já quebra toda e qualquer premissa de que o cotista não tem condições para estar na universidade, e que era um argumento que eu ouvi muito na cadeira de História da Educação. Não é o que eu cotista aqui estou vivendo, e o que as pessoas que estão aqui do meu lado estão vivendo... (RAUL)

É presente a importância e a valorização da oportunidade de integrar-se ao ensino superior, bem como a inserção social:

[...] a maioria dos alunos negros, eles dão muito valor aqui para a universidade. Isto todo mundo já comentou, mesmo quem não é cotista: - Como os cotistas dão valor para a universidade, por estar estudando na UFRGS, por estar tendo esta oportunidade. Às vezes a gente tem colegas que abandonam as cadeiras, não vão com frequência nas aulas, se passar com C tá muito bom, e os cotistas... eles dão o maior valor assim para... tem gente que "Ah, [nome do curso que frequenta], eu tô fazendo porque quero fazer um concurso assim..." E os cotistas não, eles dão um maior valor mesmo por estar aqui, estudam.... por exemplo: dois colegas nossos em Cinesio... era ele (cotista) que dava aula pra todo mundo, num grupo de estudo. Sempre todo mundo procurava ele para tirar as dúvidas, porque ele era superestudioso... Eu acho que se tu entrar aqui, com esta oportunidade que eles nos deram e tu agarras esta oportunidade, tu tens condições de vencer na vida (JOSEPHINE)

Muitas vezes os alunos precisam despender esforços maiores para acompanhar as disciplinas, porque sua escolarização nem sempre teve a qualidade esperada em sua formação. Além desse déficit em sua base de conhecimentos escolares, também ocorre, desde muito cedo, a necessidade de dedicar-se ao trabalho formal, como forma de 


\section{MARIA CRISTINA LUNARDI KERN E DENISE MACEDO ZILIOTTO}

ajudar no sustento da família:

[...] os meus colegas que... sei lá, estudavam de manhã e trabalhavam do meio dia às oito da noite e aí tinham sei lá mais o que pra fazer, mesmo que quisessem não teriam como entrar na faculdade. Acho que as cotas pega bem este público. [...] Mas tem esse outro público também, que quer muito, mas não tem como estudar, como lá o colega da escola pública, porque trabalha horrores, porque dali a pouco tem que ajudar a sustentar o irmão menor, tem que passar o dia todo correndo atrás dos irmãos, então não tem como (TALITA).

Os entrevistados também mencionam o aspecto jurídico do processo de inclusão, dos seus direitos enquanto cidadãos, quando dizem que todos têm direito a uma educação de qualidade e gratuita, e que isso de certa forma está sendo contemplado pela política de cotas:

[... a afinal a universidade é uma universidade federal, as pessoas pagam seus impostos. Todos pagam seus impostos, e parte dessa verba é investida aqui, neste ensino. Então, ela tem que ser aberta para todos, nem que tenha que haver este tipo de política que para muitos é injusto (JOYCE).

Um entrevistado declara que a política está sendo muito positiva, e esse é o momento da classe média baixa, negros, brancos e índios, se firmarem e mudarem o futuro para melhor, transformando uma sociedade que está conformada com o contexto social em que vive:

[...] o pessoal da classe média baixa que vive numa situação desconfortável para a sua família ou... e que vê o que acontece, e que de alguma forma entrando numa universidade, tenta transformar o futuro para algo melhor. É tentar transformar isso para algo melhor, tentar transformar nosso futuro, sabe?... Tentar deixar de ser uma mesmice... eu estou vendo aquele guri ali que mora numa favela e eu sei o futuro dele, ele vai ser aquilo ali... Não! Pensar diferente: ele mora na Cruzeiro, por exemplo, na Vila Cruzeiro... e aí? Vamos apoiá-lo. Ele vai poder entrar num curso de medicina, por exemplo. Por que não? Por que ele não pode estudar?... Esta política proporciona isto, dependendo das pessoas se interessarem e se engajarem nessa... (KALEO).

Ao serem inqueridos em que momento(s) se sentiram verdadeiramente incluídos na universidade pública, os cotistas dizem sentirem-se adaptados e incluídos, expressando em diversos aspectos como isso se constituía. Quando, por exemplo, têm um bom desempenho acadêmico, o que remete à questão do mérito:

Quando tiro boas notas, nas apresentações de trabalhos. Apresento um bom lá na frente assim, que as pessoas te valorizam... sempre me esforcei para ir bem assim e daí tu vê que as pessoas te chamam pra tu fazer parte do grupo: "Ah, vamos fazer, posso fazer contigo, vamos fazer?". Vêm te procurar até fora da sala de aula. "Ah, tu já tem grupo? Tu não quer fazer comigo?" Tu te sente mais incluída. Mais nesse sentido a gente se sente incluído, sabe? Quando tu mostra boas notas, aí tu vê que as pessoas te chamam, te valorizam. "Ah, ela é negra, mas não é tão burra", alguma coisa assim (JOSEPHINE).

Entendem que só o fato de estarem na universidade já faz com que se sintam incluídos:

No cotidiano, eu posso dizer que muito assim... A minha bolsa é de manhã, aí na terça e na quinta eu tenho aula e depois eu venho pra cá e vivo nessa função, indo de campus em campus. E é uma coisa que está na minha vida, girando em torno disso, da universidade, dos meus estudos, e fora essas outras atividades acadêmicas que eu tenho participado, que eu estou gostando bastante de participar (TALASSA).

Segundo Carvalho (2005b), não se pode esperar que o ensino público fundamental e o médio melhorem sua qualidade para então os negros terem condições de concorrer igualmente com os demais, pois levaríamos 32 anos para que essa igualdade fosse alcançada. Uma vez que a política 
de cotas vem sendo implementada nas universidades brasileiras, já é possível observar, na fala dos alunos cotistas, que é visível o aumento do número de negros nos cursos de graduação. As deficiências apresentadas pelos alunos cotistas, principalmente quanto ao ensino básico, podem ser amenizadas por meio das ações inclusivas propostas e pelo interesse do aluno, juntamente com a primazia da construção de uma sociedade mais inclusiva.

\section{CONSIDERAÇÕES FINAIS}

A partir dos dados compartilhados, evocados pelas diferentes fontes pesquisadas, visando analisar a efetividade do sistema de cotas raciais na universidade pública, percebe-se que os cotistas possuem trajetórias semelhantes no enfrentamento de problemas advindos da formação escolar insuficiente, impactando no ingresso na universidade como uma superação de suas condições sociais e pessoais. Pode-se refletir o quanto esses problemas são característicos de minorias que viveram em posição social subalterna por um período muito longo de tempo. Nesse sentido, o processo de inclusão no ensino superior público pode representar uma mudança nas condições sócio-históricas a partir do sentimento de pertencimento que os cotistas possam passar a vivenciar.

Por meio deste estudo, pode-se constatar que a política de cotas é uma política inclusiva para alunos autodeclarados negros nos seguintes aspectos: na possibilidade de acompanhar e até superar os demais colegas, o que contrapõe o discurso de teóricos que se opõem à ação afirmativa de que os alunos autodeclarados negros não conseguiriam dar continuidade aos estudos em uma universidade em função de o ensino fundamental $e$ o médio serem defasados; na quase inexistência de manifestações discriminatórias em relação aos alunos cotistas autodeclarados negros no meio acadêmico, o que também contrapõe o discurso de que essa política seria mais uma forma de segregação na universidade; na participação e atuação dos cotistas na pesquisa, no ensino e na extensão; na inserção de alguns no mercado de trabalho a partir da formação iniciada na universidade, que lhes dá uma perspectiva de melhor colocação no mercado de trabalho após formação; no crescimento pessoal e social a partir da possibilidade de vivenciar o ensino superior, dessa forma estimulando familiares, amigos e futuras gerações para essa conquista.

As questões que ainda apontam para uma condição pouco inclusiva são a restrita visibilidade para o processo na universidade, seja no reconhecimento como também no dificultado acesso aos cotistas, na discussão extremamente setorial sobre essa inclusão que não chega a pensar os efeitos na instituição de ensino a partir de uma óptica mais ampla. Com a justificativa de não repetir a segregação e a discriminação historicamente impostas aos negros, a não identificação e consequente reserva em explicitar tal processo acaba, por vezes, silenciando diante de uma situação que ainda não alcança real reconfiguração dos laços de pertencimento social. O índice reduzido de docentes negros nas universidades também revela outra faceta desse contexto, que se presentifica igualmente na participação restrita dos cotistas nos eventos promovidos pela instituição, bem como no seu estranhamento inicial por estarem fazendo parte de algo que lhes era impensável anteriormente, a formação universitária.

Enquanto processo em construção e avaliação, entende-se que historicamente tais condições possam vir a ser superadas, mas atualmente refletem os traços que marcam a sociedade, a cultura e os valores do contexto acadêmico. Como limitações desta pesquisa podem-se apontar a amostra não probabilística, o corte transversal da investigação e as dificuldades encontradas para obter 
dados atinentes aos alunos cotistas na instituição em estudo. Nesse sentido, futuras investigações acerca da efetividade e mesmo da continuidade da ação afirmativa de cotas no ensino superior brasileiro poderão desenvolver estudos longitudinais, comparativos, ou mesmo estabelecer avaliações a partir de outros resultados disponíveis, como desdobramentos de um processo histórico-social em curso.

\section{NOTAS}

${ }^{1} \mathrm{O}$ termo 'ação afirmativa' refere-se a um conjunto de políticas públicas para proteger grupos que, em uma determinada sociedade, são ou tenham sido discriminados. A ação afirmativa visa remover barreiras, formais e informais, que impeçam o acesso de certos grupos ao mercado de trabalho, universidades e posições de poder. Nessa perspectiva, a sub-representação de minorias em instituições e posições de maior prestígio na sociedade é considerada um reflexo de discriminação. Portanto, visa-se, por um período provisório, a criação de incentivos que busquem certo equilíbrio da representatividade dos diversos grupos que fazem parte de determinada sociedade, nesses espaços (OLIVEN, 2009, p. 67).

2 Autodeclarados negros são alunos negros oriundos de escolas públicas os quais se inscrevem para o vestibular na modalidade de cotas para negros e que, se aprovados, no momento da matrícula, devem assinar uma autodeclaração de que são negros, na presença de membros da Comissão de Graduação.

3 Bolsa Permanência - Oportuniza ao estudante desenvolver atividades na UFRGS, como forma de garantir o custeio da vida acadêmica. Tem como pressuposto proporcionar experiência profissional, nos níveis técnico e administrativo, complementando a formação acadêmica e recebendo auxílio financeiro $O$ critério de concessão da bolsa é o benefício adquirido por meio da análise da situação socioeconômica e de desempenho escolar do aluno. Bolsa REUNI - O objetivo é garantir aos alunos carentes a permanência qualificada na universidade, por meio da assistência estudantil. Têm acesso à Bolsa REUNI somente alunos da graduação e com benefício da Bolsa Permanência.

Bolsa Treinamento - O objetivo é oportunizar o desenvolvimento de atividades de apoio administrativo, pedagógico e na área de informática, no âmbito das Unidades e Administração Central da UFRGS. Para pleitear esta bolsa não é necessário estar incluído no Programa de Benefícios SAE (UFRGS, SAE, 2010).

${ }^{4}$ I Seminário de Ações Afirmativas da UFRGS, realizado em agosto de 2010.

\section{REFERÊNCIAS}

CARVALHO, José Jorge de. Inclusão étnica e racial no Brasil: a questão das cotas no ensino superior. São Paulo: Attar, 2005a.

Inclusão étnica e racial no Ensino Superior: um desafio para as universidades brasileiras. In: NUNES, Margarete Fagundes (Org.). Diversidade e políticas afirmativas: diálogos e intercursos. Novo Hamburgo: FEEVALE, 2005b.

EDUCAFRO. Atingimos a $150^{a}$ a adotar cotas! 2010. Disponível em: <http://www.educafro.org.br/noticia. php?id $=1250 \&$ cat $=5 \&$ sub=22>. Acesso em 22 fev. 2011 .

FERREIRA, Ricardo Franklin. O brasileiro, o racismo silencioso e a emancipação do afrodescendente. Cadernos de Pesquisa SciELO. Psicologia E Sociedade, Belo Horizonte, v. 14, n. 1, p. 1-13, 2002. Doi: 10.1590/S0102-71822002000100005. Disponível em: <http://www.scielo.br/pdf/\%0D/psoc/v14n1/v14nla05.pdf>. Acesso em 14 ago. 2010.

FRY, Peter; MAGGIE, Yvonne. A reserva de vagas para negros nas universidades brasileiras. Cadernos de Pesquisa SciELO. Estudos Avançados, São Paulo, v. 18, n. 50, 2004. Disponível em: <http://www.scielo.br/scielo.php?script=sci_arttext\&pid=S0103$40142004000100008 \& \operatorname{lng}=p t \& n r m=i s o 2004>$. Acesso em 17 abr. 2010.

GOMES, Joaquim Barbosa. Ação afirmativa e princípio constitucional da igualdade. Rio de Janeiro: Saraiva, 2001.

O debate constitucional sobre as ações afirmativas. In: SANTOS, Renato Emerson dos; LOBATO, Fátima (Orgs.). Ações afirmativas: políticas públicas contra as desigualdades raciais. Rio de Janeiro: DP\&A, 2003.

HEINEN, Juliano. As ações afirmativas como instrumento promotor da educação. Revista Inclusão Social, Brasília, v. 3, n. 1, p. 24-34, 2008.

INSTITUTO Brasileiro de Geografia e Estatística (IBGE). Sintese de indicadores sociais: uma análise das condições de vida da população brasileira 2010. Rio de Janeiro: IBGE, 2010. 317 p. (Estudos e pesquisas. Informação demográfica e socioeconômica, 27) Disponível em: <http://www.ibge.gov.br/home/ estatistica/populacao/condicaodevida/indicadoresminimos/ sinteseindicsociais2010/SIS_2010.pdf>. Acesso em 21 nov. 2011.

MOEHLECKE, Sabrina. Ação afirmativa no ensino superior: entre a excelência e a justiça social. Educação e Sociedade, Campinas, v. 25, p.757-776, Especial, out. 2004.

MORCHE, Bruno; NEVES, Clarissa E. B. A questão racial no acesso ao ensino superior: políticas afirmativas e equidade. Florianópolis: Seminário Fazendo Gênero, 2010.

OLIVEN, Arabela Campos. Ações Afirmativas na Universidade Federal do Rio Grande do Sul e o seu significado simbólico. 
Revista Educação, Santa Maria, n. 1, v. 34, p. 65-76, 2009. Disponível em: <http://cascavel.ufsm.br/revistas/ojs-2.2.2/index. php/reveducacao/article/view/1589>. Acesso em: 24 ago. 2009.

PIRES, Lúcia. Como foram os cotistas no ano de estreia na UFRGS? Zero Hora, Porto Alegre, p. 22-23, 4 jan. 2009. Caderno Geral.

SANTOS, Edson. Ministro defende cotas sociais nas universidades. Brasília: Secretaria Especial de Políticas para a Promoção da Igualdade Racial, 2008. Disponível em: <www.planalto.gov.br/ seppir/>. Acesso em 14 jul. 2009.

SCHWARTZMAN, Simon. A questão da inclusão social na universidade brasileira. In: PEIXOTO, Maria do Carmo de Lacera; ARANHA, Antônia Vitória (Orgs.). Universidade pública e inclusão social: experiência e imaginação. Belo Horizonte: Editora UFMG, 2008.
TRIVIÑOS, Augusto N. S. Introdução à pesquisa em ciências sociais: a pesquisa qualitativa em educação. São Paulo: Atlas,1999.

UNIVERSIDADE FEDERAL DO RIO GRANDE DO SUL (UFRGS). Conselho Universitário. Processo de implantação e implementação das ações afirmativas de cotas na UFRGS, no 23078.013633/07-10. Porto Alegre, 2007.

COPERSE: Comissão Permanente de Seleção, 2010. Disponível em: <http://www.ufrgs.br/coperse>. Acesso em 24 abr. 2010.

VIEIRA, Andréa Lopes da Costa. Políticas de educação, educação como política: observações sobre a ação afirmativa como estratégia política. In: SILVA, Petronilha Beatriz Gonçalves; SILVÉRIO, Valter Roberto (Orgs.). Educação e ações afirmativas: entre a injustiça simbólica e a injustiça econômica. Brasília: INEP/ MEC, 2003. 270 p. 